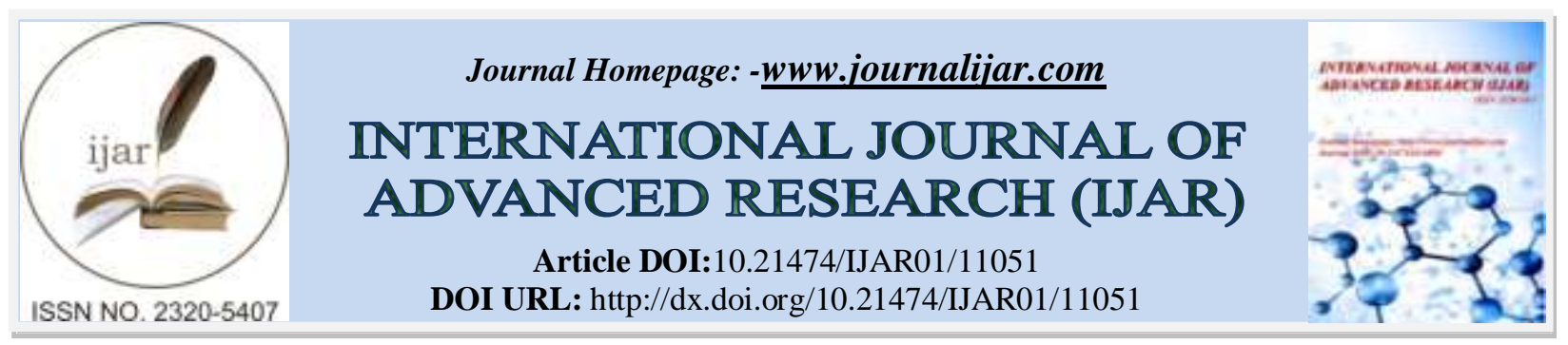

\title{
RESEARCH ARTICLE \\ PRIMITIVE HYDATIC CYST OF THE THIGH IN A YOUNG WOMEN:CASE REPORT AND LITERATURE REVIEW
}

A. Soleh, M. Haddou, E. Zim, M.A Benhima, I. Abkari and H. Saidi

Service of Orthopedic Surgery and Traumatology, CHU Mohammed VI, Marrakesh, Morocco.

\section{Manuscript Info \\ (......................... \\ Manuscript History \\ Received: 25 March 2020 \\ Final Accepted: 30 April 2020 \\ Published: May 2020 \\ Key words: - \\ Hydatid Cyst, Thigh, Surgery, Case Report}

\begin{abstract}
Muscular hydatidosis is a rare condition that accounts for less than $1 \%$ of all hydatid cysts cases, its asymptomatic character and its slow evolution are the main cause behind delayed diagnosis. The use of imaging modalities such as MRI contributes significantly to the diagnosis. The Treatment is based on the surgical excision of the cyst.We report a rare case of30-year-old women with a primitive hydatid cyst of thethigh revealed byprogressive swelling.
\end{abstract}

Copy Right, IJAR, 2020. All rights reserved.

\section{Introduction:-}

Hydatid disease is a common parasitic infection in endemicareas including North Africa, the Middle East, and South America, where it's considered apublic health problem. It's a zoonotic disease caused by tapeworms of the genus Echinococcus, transmitted accidentally to human by ingesting the parasite eggs [1].

Muscular localization is uncommon, its incidence is less than $0.5 \%$ of all cases. this can be explained by the presence of lactic acid in muscle tissue and oxygen deficiency preventing implantation and scolex development $[2,3]$.

The silent evolution of the disease and the asymptomatic character lead to delayed diagnosis, discovery can be made accidentally or after complications [4].

We report the case of a primary hydatid cyst in 30-year-old women revealed by swelling of the medial compartment of the thigh.

\section{Case presentation:}

A 30 year-old housewife, without known pathological history, with notion of contact with dogs since childhood,presents for a mass of the internal face of the right thigh gradually increasing in volume for the past 6 months.Clinical examination found a patient in good general condition, apyretic, with a voluminous masse in the proximal part of medial compartment of the right thigh, measuring $13 * 6 \mathrm{~cm}$, painless, without local inflammatory signs, fixed to the deep plan with homolateral subcentimetricinguinallymphadenopathies without signs of vascular or nervous compression (fig.1). The abdominal and respiratory examination were normal.

Corresponding Author:- A. Soleh

Address:- Service of Orthopedic Surgery and Traumatology, CHU Mohammed VI, Marrakesh, Morocco. 


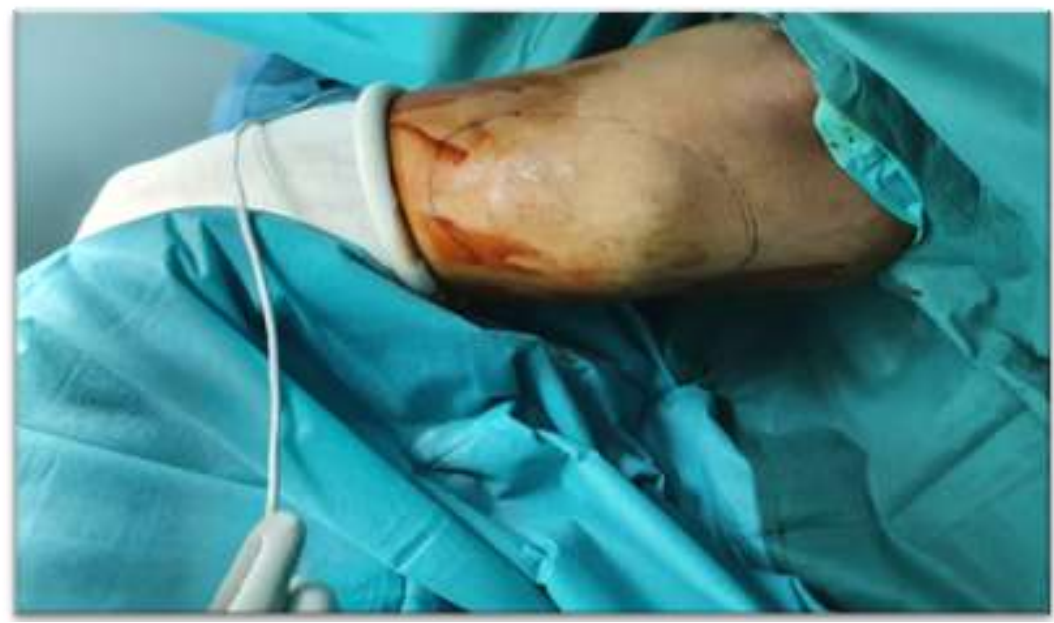

Fig 1:- Mass on the medial side of the thigh.

The standard radiography had shown a thickening of the surroundingsoft tissues, without bone involvement or calcifications (fig. 2). The ultrasound showed multiple fluid-containing cysts with well-defined and individualized capsule.The MRI had identified cystic formations in the adductor magnus muscle and semitendinousus muscle in low signal on $\mathrm{T} 1$ weighted sequence and high signal in $\mathrm{T} 2$ weighted sequence without endocystic partition or vegetation (fig.3).The hydatid serology was positive. The blood test and the investigation for other locations (abdominal ultrasound; chest x-ray) were normal.

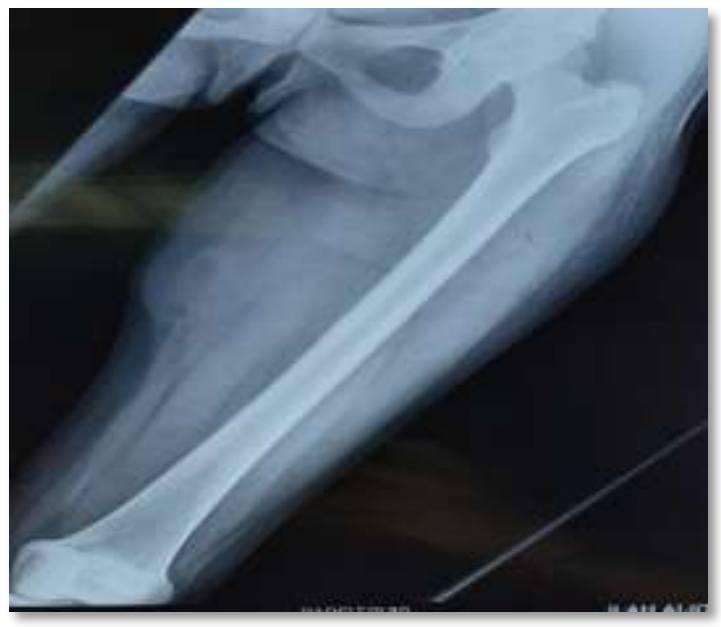

Fig 2:X-Ray:Thickening of the soft tissue at the medial compartment of the thigh.
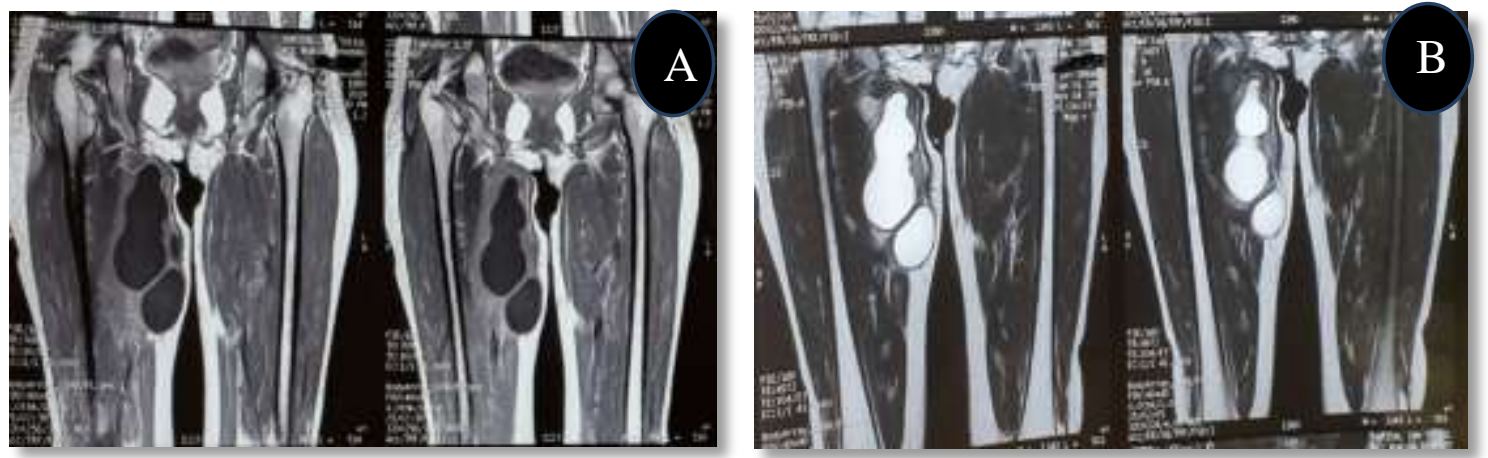

Fig 3:- MRI: intramuscular hydatid cyst with hyposignal (A) in T1-weighted sequence and hypersignal in T2 weighted sequence (B). 
A careful surgical excision was performed (fig. 4,5) without anyperioperative incidents, and the postoperative follow-up was without complications. The anatomic pathology examination of spicemen confirmed the diagnosis of hydatid cyst. After a 12-month follow-up nosign of local or visceral recurrence has been detected.

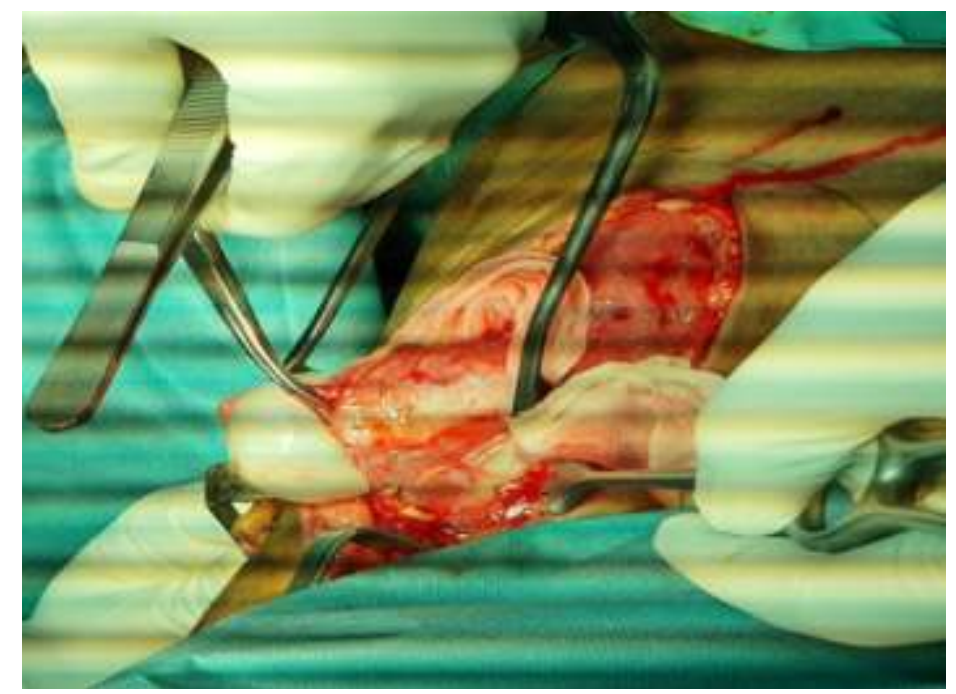

Fig 4:- Intraoperative view of precystectomy.

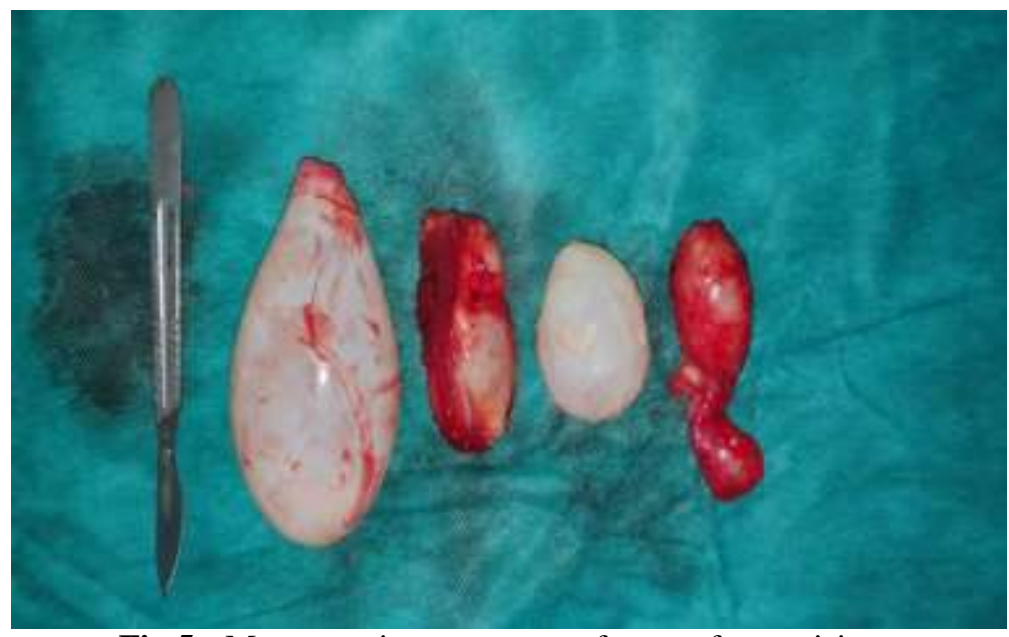

Fig 5:- Macroscopic appearance of cysts after excision.

\section{Discussion:-}

Echinococcosis is a cosmopolitan antropozoonosis common to humans and many mammals owing to the development of the larval or hydatic form of a dog tapeworm called ECHINOCOCCUS GRANULOSUS[5,6].

The muscle constitutes an environment unfavorable for the development of the larva. Hexacanth embryos arriving in the digestive tract are most often stopped by the liver and lungs acting as physiological filters. A very small number of embryos arrive in the large circulation where they spread throughout the body [7].Several muscle locations have been described, with the predominant involvement of the neck, trunk, and limbs, particularly those of the lower limb (quadriceps; sartorius and gluteus)[8].

Clinically, the symptomatology of muscular hydatidosis is not specific. It is usually a soft tissue tumor, with very slow evolution making the diagnosis challenging. symptoms are more manifest on occasion ofcomplications (bacterial infectionorrupture) [6,8]. 
The role of MRI is indisputable in the exploration of hydatid disease, it aids in the proper analysis of the mass (characteristics, dimensions, reports ...),MRI also helps to eliminate possible differential diagnoses and support a precise assessment of lesions before surgery $[9,10]$.

Hydatid serology allows to retain diagnosis when it's positive, however, false negative results shows up in $80 \%$ of confirmed cases.Hyperosinophilia is usually absent except when a rupture occurs[7].

total pericystectomyremains the treatment of choice in the management of muscular hydatidosis,thesurgeonmust be careful to avoid intraoperative rupture of the cyst.The use of surgical gauze swabs immersed in scolicidal agent or hypertonic solution helps to prevent the spread of the parasite and reduce the risk of soiling, contamination and diseaserecurrence $[4,11]$.

The use of albendazole has not been shown to be effective in cases of hydatid muscular cyst,despite this, it keeps an indication in inoperable patients or in recurrencecases. [12]

\section{Conclusion:-}

Muscular localization in hydatid disease is exceptional even in endemic countries, with insidious and non-evocative symptoms at the origin of frequently delayed diagnosis. The diagnosis relies essentially on MRI, while biology provides additional elements. The best treatment remains prevention and early diagnosis.

\section{Conflicts of interest:}

The authors declare that they have no conflicts of interest in relation to this article.

\section{Author contributions:}

All the authors contributed to the conduct of this work. All authors also declare having read and approved the final version of the manuscript.

\section{References:-}

1. Dumon H, Quilici M. La maladie hydatique : parasitologie épidémiologie et prophylaxie. Rev Prat. 1978;28:2827-2834.

2. Sharif Tahir AM, Bahjat AS, Mohammed AA. Primary infected hydatid cyst of the thigh in a young lady; case report with literature review. Ann Med Surg 2012. nov2019;47:32-5.

3. Kazakos CJ, Galanis VG, Verettas D-A, Polychronidis A, Simopoulos C. Primary hydatid disease in femoral muscles. J Int Med Res. 2005;33(6):703-706.

4. Omezzine SJ, Abid F, Mnif H, Hafsa C, Thabet I, Abderrazek A, Sassi N, Hamza HA. Kyste hydatique primitif de la cuisse. Une localisationrare. /data/revues/18770517/v96i1/S1877051709004328/. 16 févr2010.

5. Henri D. Echinococcus granulosus. 2007.

6. Benhaddou H, Margi M, Kissra M, Benhmamouche MN. Le kyste hydatique du muscle trapezius : une localisation inhabituelle. Arch Pédiatrie. 2010;17(3):263-265.

7. Mzabi R, Dziri C. Extrahepatic echinococcosis: diagnosis and treatment. Rev Prat.1990;40(3):220-224.

8. 8. Kurz K, Schwabegger A, Schreieck S, Zelger B, Weiss G, Bellmann-Weiler R. Cystic echinococcosis In the thigh: a case report. Infection. avr 2019;47(2):323-9.

9. Ben M'Rad S, Mathlouthi A, Merai S, Ghrairi H, Mestiri I, Ben MiledM'Rad K, Djenayah F. [Multiple hydatid cysts of the thigh: the role of magnetic resonance imaging]. J Radiol. sept 1998;79(9):877-9.

10. Cissé AM, Nassar I, Hammani L, Dafiri R, Imani F. Primary extensive hydatidosis of the thigh: unusual radiological aspects. J Radiol. 2002;83(11):1778-1780.

11. Mseddi M, Mtaoumi M, Dahmene J, Hamida RB, Siala A, Moula T, Ayeche MB. Kyste hydatique musculaire: à propos de 11 cas. Rev Chir Orthopédique Réparatrice Appar Mot.2005;91(3):267-271.

12. Carpintero P, Kindelan J, Montero R, Carpintero A. Primary hydatidosis of the peripheral muscles: treatment with albendazole. Clin Infect Dis. 1997;24(1):85- 86. 